\title{
Older adults' preferences for colorectal cancer-screening test attributes and test choice
}

\author{
This article was published in the following Dove Press journal: \\ Patient Preference and Adherence \\ 15 July 2015 \\ Number of times this article has been viewed
}

\author{
Christine E Kistler ${ }^{1-3}$ \\ Thomas $\mathrm{M} \mathrm{Hess}^{4}$ \\ Kirsten Howard ${ }^{5,6}$ \\ Michael P Pignone $2,3,7$ \\ Trisha M Crutchfield ${ }^{2,3,8}$ \\ Sarah T Hawley' \\ Alison T Brenner ${ }^{2}$ \\ Kimberly T Ward ${ }^{2}$ \\ Carmen L Lewis ${ }^{10}$ \\ 'Department of Family Medicine, \\ School of Medicine, ${ }^{2}$ Cecil G Sheps \\ Center for Health Services Research, \\ ${ }^{3}$ Lineberger Comprehensive Cancer \\ Center, University of North \\ Carolina at Chapel Hill, Chapel Hill, \\ ${ }^{4}$ Department of Psychology, North \\ Carolina State University, Raleigh, \\ NC, USA; ${ }^{5}$ nstitute for Choice, \\ University of South Australia, Sydney, \\ NSW, Australia; ${ }^{6}$ School of Public \\ Health, University of Sydney, Sydney, \\ NSW, Australia; ${ }^{7}$ Division of General \\ Internal Medicine, School of Medicine, \\ ${ }^{8}$ Center for Health Promotion and \\ Disease Prevention, University of \\ North Carolina at Chapel Hill, Chapel \\ Hill, NC, ' ${ }^{9}$ epartment of Medicine, \\ University of Michigan, Ann Arbor, \\ MI, ${ }^{10}$ Division of General Internal \\ Medicine, Department of Medicine, \\ University of Colorado School of \\ Medicine, Aurora, CO, USA
}

Correspondence: Christine E Kistler Department of Family Medicine, University of North Carolina at Chapel Hill, 590 Manning Drive - CB 7595,

Chapel Hill, NC 27599, USA

$\mathrm{Tel}+\mid 9193958621$

Fax + I 9199666126

Email christine_kistler@med.unc.edu
Background: Understanding which attributes of colorectal cancer (CRC) screening tests drive older adults' test preferences and choices may help improve decision making surrounding CRC screening in older adults.

Materials and methods: To explore older adults' preferences for CRC-screening test attributes and screening tests, we conducted a survey with a discrete choice experiment (DCE), a directly selected preferred attribute question, and an unlabeled screening test-choice question in 116 cognitively intact adults aged 70-90 years, without a history of CRC or inflammatory bowel disease. Each participant answered ten discrete choice questions presenting two hypothetical tests comprised of four attributes: testing procedure, mortality reduction, test frequency, and complications. DCE responses were used to estimate each participant's most important attribute and to simulate their preferred test among three existing CRC-screening tests. For each individual, we compared the DCE-derived attributes to directly selected attributes, and the DCE-derived preferred test to a directly selected unlabeled test.

Results: Older adults do not overwhelmingly value any one CRC-screening test attribute or prefer one type of CRC-screening test over other tests. However, small absolute DCE-derived preferences for the testing procedure attribute and for sigmoidoscopy-equivalent screening tests were revealed. Neither general health, functional, nor cognitive health status were associated with either an individual's most important attribute or most preferred test choice. The DCE-derived most important attribute was associated with each participant's directly selected unlabeled test choice.

Conclusion: Older adults' preferences for CRC-screening tests are not easily predicted. Medical providers should actively explore older adults' preferences for CRC screening, so that they can order a screening test that is concordant with their patients' values. Effective interventions are needed to support complex decision making surrounding CRC screening in older adults.

Keywords: colorectal cancer screening, patient preferences, values clarification, discrete choice experiment, conjoint analysis, test attributes

\section{Introduction}

Colorectal cancer (CRC) is one of the top three leading causes of cancer death in the US, and its incidence increases with age. ${ }^{1}$ Guidelines for CRC screening recommend routine screening from age 50-75 years, and individualized screening decisions in adults aged 76-85 years (American Cancer Society, ${ }^{2}$ United States Preventive Services Task Force, ${ }^{1}$ and American Geriatrics Society ${ }^{3}$ ), based on life expectancy and health status. National survey data suggest that over a third of US adults aged 50-75 years are not up to date with screening, ${ }^{4}$ and $23 \%$ of adults aged $76-84$ years have never been screened. ${ }^{5}$ Successful interventions to improve CRC screening range from system-level to patient-level changes to reduce barriers to $\mathrm{CRC}$ screening. However, the evidence on how to improve patient-provider discussions about CRC screening is limited. ${ }^{6}$ 
Evidence suggests patients are more likely to undergo screening if they are educated about screening options and have the ability to select the screening method. ${ }^{7}$ Ideally, once a decision has been made to pursue CRC screening, an individual will be educated on screening options and will select a screening method after a discussion in conjunction with their provider. Deciding which screening test to use can be challenging; there are several effective, evidence-based options from which to choose, including fecal occult blood test (FOBT), sigmoidoscopy, and colonoscopy. ${ }^{8}$ Each screening method has its own set of characteristics or "attributes" that can influence decisions, such as risk of complications, test sensitivity, preparation procedures, and recommended frequency. ${ }^{1}$ Unfortunately, adult patients rarely have individualized discussions with their providers regarding screening options or the selection of a screening test. If a conversation does occur between patient and provider, these discussions seldom consider patients' preferences. ${ }^{9,10}$

A stated-choice methodology known as discrete choice experimentation has been used over the past 20 years to assess preferences for health care services and policies. ${ }^{11}$ The method elicits preferences for hypothetical products or service features, and indicates which features are most important to an individual or group. Data from CRC discrete choice experiments (DCEs) have been used extensively to provide insight into preferences for $\mathrm{CRC}$-screening tests and programs. ${ }^{12}$ Although CRC DCEs have been conducted in middle-aged adults, ${ }^{12-23}$ to our knowledge no DCE work has examined the preferences for CRC-screening tests specifically in older adults aged 70 years or older. Given older adults' increasing levels of comorbidity, increased risk of complications and decreasing life expectancy, ${ }^{24,25}$ their preferences for CRC-screening tests may differ from those of other age-groups. Understanding which attributes of CRC-screening tests drive older adults' test preferences and choices may help improve decision making surrounding CRC screening in older adults, because it will enable providers to tailor their discussions to the information that is most important to their patients.

To explore older adults' preferences for CRC-screening test attributes and test choices, we surveyed older adults. We used a DCE to assess preferences for test attributes, and also asked participants to directly select the test attribute they felt was the most important feature of the screening tests, which we call the "most important attribute". We then compared the DCE-derived most important attribute with the directly selected most important attribute. Additionally, we used the DCE data in a simulation model to predict the screening test option, which appears most consistent with each participant's preference for a particular set of attributes. Lastly, we compared the simulated screening test result to individuals' directly selected unlabeled test choice.

\section{Materials and methods Survey overview}

Using computer-aided personal interviewing, participants completed a questionnaire regarding preferences for CRCscreening tests and test features. Given concerns about older adults' ability to use the computer-aided personal interviewing system, a study-team member operated the computer and helped participants throughout the data-collection process. Additionally, team members were available to read questions for participants when necessary. The study was conducted with the approval of the institutional review board at the University of North Carolina at Chapel Hill.

Before taking the survey, participants received basic education about CRC and CRC-screening risks and benefits. Participants also received a general description of the attributes and corresponding levels used throughout the survey. The survey included basic sociodemographic and functional status questions, including a depression screen (Patient Health Questionnaire 2), dementia screen (six-item recall), literacy score (Short Form Rapid Estimate of Adult Literacy in Medicine), the MacArthur Scale of Subjective Social Status, and a 4-year mortality index. Given the hypothesis that unhealthier older adults might prefer different test attributes than their healthier counterparts, we also evaluated participants' general, physical, and executive function. General health was obtained via the one-item self-reported health assessment (ie, the SF-1). ${ }^{26} \mathrm{~A}$ team member assessed participants' physical health via the timed up-and-go test. ${ }^{27}$ This timed test starts with the subject standing from a chair, walking 10 feet $(3.05 \mathrm{~m})$, and returning to the chair, and ends after the subject sits back down in the chair. ${ }^{28}$ The average time in this population is 9 seconds. ${ }^{29}$ Executive function was measured using the Trail-Making Test B. With alternating letters and numbers, the Trail-Making Test $\mathrm{B}$ is a timed test with an average score in 70- to 74-year-old adults of 97 seconds. ${ }^{30}$ Moreover, the questionnaire consisted of two forms of preference elicitation: a DCE and direct preference selection (ranking). ${ }^{31}$

\section{Discrete choice experiment development}

In a DCE, individuals select between hypothetical alternatives that are described by attributes and their corresponding levels (Table 1). Each level of the attributes is varied systematically in a series of choice tasks where individuals select the option they prefer the most. Options are designed 
Table I Final attributes, levels, and mean utilities $(n=\mid 16)$

\begin{tabular}{llll}
\hline Attributes & Levels & Mean, raw utilities & $P$-values \\
\hline What you need to do to complete & No preparation time, home test, mild & 0.43 \\
the test & discomfort, no recovery time & \\
& Half-day preparation, test in medical facility, & 0.04 \\
& moderate discomfort, I-hour recovery & \\
& Full-day preparation, test in medical facility, & -0.47 \\
& moderate discomfort, 24-hour recovery & \\
How much the test decreases your & Five in I,000 people don't die of cancer because & -0.40 \\
chance of dying from cancer & of the test & 0.01 \\
& Ten in I,000 people don't die of cancer because & \\
& of the test & 0.39 \\
& 20 in I,000 people don't die of cancer because & \\
How often you have to repeat & of the test & -0.25 \\
the test & Every year & 0.24 \\
The risk of complications & Every 5 years & 0.01 \\
& Every I0 years & 0.24 \\
One in I,000 & Five in I,000 & 0.12 \\
\hline None & Ten in I,000 & -0.36 \\
\hline
\end{tabular}

to provide numerical information about the relative value individuals attach to the different levels of the attributes. ${ }^{32}$ It is essential to identify and detail the most salient attributes and levels that factor into decision making when designing a DCE. ${ }^{33}$

We initially identified the attributes and levels for the DCE through a literature review. ${ }^{17,18}$ For example, we based the levels of the attribute, "risk of complications", on the frequency of complications from receipt of a colonoscopy, because any positive screening test will require a colonoscopy. ${ }^{34,35}$ Individual qualitative interviews were conducted with 41 adults aged 70 years and older from January to March 2011 to refine the attributes and levels used in the DCE. The wording and number of discrete choice questions, attributes, and levels were modified based on the qualitative interviews. Attributes such as cost or insurance coverage were omitted from the experiment, because most older adults in the US have Medicare, which covers CRC screening. Additionally, by observing and questioning about participant fatigue in the qualitative interviews, the optimal number of discrete choice questions was determined to be between ten and 12 questions. The final list of attributes and corresponding levels was reached through an iterative process using qualitative interviews, including direct questioning and observation (Table 1).

\section{Discrete choice experiment design}

The International Society for Pharmacoeconomics Outcomes Research (ISPOR) Guidelines for Good Research Practices for Conjoint Analysis in Health were followed in the development of the DCE. ${ }^{36}$ The DCE was created using a fractional factorial design with ten discrete choice questions using SSI Web 7 software (Sawtooth Software Inc, Orem, UT, USA). The DCE asked participants to choose the most preferred of two hypothetical CRC-screening tests that vary in their levels for each of the four attributes or to select a "none" option, representing a decision not to be screened by either of the two presented tests. Fifteen versions of the DCE were generated with randomly ordered attributes and discrete choice questions to reduce the risk of attribute-ordering bias (Figure 1).

Given concerns about cognitive impairment in this population, ${ }^{37}$ a dominant discrete choice question was included in the DCE to ensure participants understood the DCE selection process. In a dominant discrete choice question, one of the two choices contains only the most desirable levels of the attributes, (eg, least invasive, best mortality reduction, fewest complications, and least frequent), while the other choice contains only the least desirable levels of the attributes (eg, most invasive, least mortality reduction, most complications, and most frequent). A participant who was unable to understand that one test was superior or dominant to the other was considered unable to complete the remainder of the choice questions.

\section{Directly selected most important attribute and preferred test choice}

Direct preference selection consisted of asking participants to rank the four attributes in order of importance. The attribute 
These are not real tests, but if these were YOUR only options, which would YOU choose?

Choose by clicking one of the buttons below:

Test A

\begin{tabular}{|c|c|c|}
\hline $\begin{array}{l}\text { The decrease in your } \\
\text { chance of dying }\end{array}$ & $\begin{array}{l}20 \text { in } 1,000 \text { people don't die of cancer } \\
\text { because of the test }\end{array}$ & $\begin{array}{l}10 \text { in } 1,000 \text { people don't die of cancer } \\
\text { because of the test }\end{array}$ \\
\hline $\begin{array}{l}\text { How often you need to } \\
\text { repeat the test }\end{array}$ & Every year & Every 10 years \\
\hline $\begin{array}{l}\text { The risk of } \\
\text { complications }\end{array}$ & 1 in 1,000 & 5 in 1,000 \\
\hline $\begin{array}{l}\text { What you need to do } \\
\text { to complete the test }\end{array}$ & $\begin{array}{l}\text { Full-day preparation, test in medical } \\
\text { facility, moderate discomfort, } 24 \text { hours } \\
\text { recovery }\end{array}$ & $\begin{array}{l}\text { Half-day preparation, test in medical } \\
\text { facility, moderate discomfort, } 1 \text { hour } \\
\text { recovery }\end{array}$ \\
\hline
\end{tabular}

None: I would not choose either of these

Figure I Example of one of ten DCE questions.

Abbreviation: DCE, discrete choice experiment.

ranked first was considered the most important attribute. Individuals were also asked to choose an unlabeled screening test that mimicked the attributes of existing evidence-based CRCscreening tests: FOBT, sigmoidoscopy, and colonoscopy. An FOBT-equivalent test was described as an annual home test with no preparation, no recovery, mild discomfort, $0.5 \%$ reduction in mortality, and a $0.1 \%$ risk of complications. (If an individual has a positive FOBT, he or she will need to have a colonoscopy; colonoscopy risk was used as an FOBT attribute.) A sigmoidoscopy-equivalent test was described as a test performed every 5 years in a medical facility with a half-day preparation, moderate discomfort, 1-hour recovery, a $1.0 \%$ reduction in mortality, and a $0.5 \%$ risk of complications. A colonoscopy-equivalent test was described as being a decennial test performed in a medical facility with a full day of preparation, full day of recovery, moderate discomfort, a $2.0 \%$ reduction in mortality, and a $1.0 \%$ risk of complications. Individuals were also given the option to decide not to be screened for colon cancer (Figure 2).

\section{Data collection}

Data were collected from March to December 2011 from 116 individuals. Individuals were excluded from participating in the study if they had participated in the qualitative work to develop the DCE attributes, had a cognitive impairment (ascertained during the survey with a six-item screener), ${ }^{38}$ or had language barriers, including being non-Englishspeaking, having aphasia, or having a serious hearing impairment.

Two team members enrolled a volunteer sample of community-dwelling older adults (ie, older adults not residing in a long-term care facility or other institution) aged 70-90 years, with no personal history of CRC or inflammatory bowel disease. We chose this age range because individuals continue to receive screening well beyond recommended ages. ${ }^{39-41}$ In particular, we wanted to see if the older population (ie, those most likely to have the worst overall health, physical health, and executive function) might choose different tests compared to younger and healthier participants. Individuals were recruited from an academic family medicine clinic at the University of North Carolina at Chapel Hill and at North Carolina State University's Adult Development Laboratory, which conducts behavioral research on older adults. These sites were chosen because of convenience and because they draw from two distinct populations: a single primary care clinic that sees patients from across North Carolina, and a large nonmedical research registry from the large metropolitan center of Raleigh, North Carolina. 
If your doctor asked you to choose a colon cancer screening test today, and

these were the only options, which would you choose?

- I would want a home test that has no preparation time, no recovery time, mild discomfort, repeated every year, that reduces death from colon cancer by 5 in 1,000, and has a 1 in 1,000 risk of complications.

- I would want a test in a doctor's office that has a half-day preparation, 1 hour recovery, moderate discomfort, repeated every 5 years, that reduces death from colon cancer by 10 in 1,000, with a 5 in 1,000 risk of complications.

I would want a test in the doctor's office that has a full-day preparation, full-day recovery, moderate discomfort, repeated every 10 years, that decreases death from colon cancer by 20 in 1,000, with 10 in 1,000 risk of complications.

I prefer not to get screened for colon cancer.

Figure 2 Directly selected unlabeled test-choice question.

Because there is no optimal way to determine a sample size for a DCE, we used Johnson's method of optimal design to determine that a sample size of over 100 participants would provide an average D-efficiency score of 99.7, given the use of ten choice tasks, two active alternatives, and a maximum number of levels within a single attribute of three. ${ }^{42}$ Consequently, we aimed to recruit more than 100 individuals for the study.

\section{Data analysis}

The DCE responses were analyzed to estimate the implicit preference or "utility" for the different levels of each attribute. ${ }^{43}$ This was completed using a hierarchical Bayes model with Monte Carlo Markov Chain algorithms in Sawtooth Software's choice-based conjoint (CBC) analysis software module. . $^{44,45}$ Utilities are values that represent the relative desirability of the levels within each attribute in numerical form: the higher the value, the more desirable the level is to participants, and conversely the lower (more negative) the number, the less desirable the level is to participants. The individual utilities within each attribute were used to calculate attribute-importance scores, with each attribute's importance being determined by the range across its levels over the total range across all attributes. ${ }^{32}$ We calculated both the average utility scores across the sample and an individual-level most important attribute. The attribute with the highest importance score was considered the most important attribute for that participant.

We also used a CBC analysis simulation to generate a DCE-derived preferred test based on individual participant's utility scores for each attribute. ${ }^{46}$ We simulated three tests in the simulation model, which included FOBT, sigmoidoscopy, and colonoscopy. We used the same parameters in the simulation model that were used to describe the unlabeled test question. The simulated screening test with the highest total utility was regarded as a participant's preferred test. Individual test preferences were derived using the "share of preference" marketsimulation method in the Sawtooth Market Research Tool (SMRT) market simulator. This form of market simulation uses proportional allocation to generate the shares of preference for each of the three simulated test choices. The preferred test is considered the test option with the greatest shares. ${ }^{47}$

The DCE-derived most important attribute and the DCE-derived preferred test were then compared to the directly selected most important attribute and the unlabeled test-choice question, respectively. Because these data were paired, we used a $\chi^{2}$ test of symmetry to examine differences in responses. Agreement between methods was assessed using the $\kappa$-statistic. We also compared each participant's DCE-derived most important attribute with their directly selected unlabeled test choice using Pearson's $\chi^{2}$ to examine if the DCE results were consistent with their directly selected test choice.

An exploratory analysis of participant characteristics was conducted to examine whether health status, functional status, or cognitive status was associated with any particular DCEderived most important attribute or preferred test. All statistical analyses were performed using either Sawtooth Software or Stata/SE 11.2 (StataCorp, College Station, TX, USA).

Lastly, participants were asked to explain their response to the directly selected unlabeled test choice. Two authors (CEK and $\mathrm{KW}$ ) performed a content analysis of these responses and independently developed common themes in an iterative 
process. Once these were finalized, they analyzed and coded the responses for the most common themes. Disagreements were resolved through discussion until they reached consensus. ${ }^{48}$

\section{Results}

Of 277 potentially eligible participants who were approached, 67 were determined ineligible: nine were unable to complete the "dominant choice" question, four had either a prior history of CRC or had active CRC, and the remainder were ineligible due to lack of English fluency, memory problems, or had participated in the qualitative development of the DCE. Of the 210 eligible participants, 94 individuals declined participation due to time constraints or lack of interest; 116 individuals completed the final survey, which took 34 minutes on average to complete. Participants were predominantly white $(82 \%)$, female $(53 \%)$, college graduates (61\%), had been screened for CRC (92\%), and had a median age of 74 years (range 70-90 years) (Table 2 ).

\section{Overall DCE-derived preferences for test attributes and their corresponding levels}

Mean utility scores are shown in Table 1. Individuals showed a preference for less invasive test-attribute levels. Participants

Table 2 Participant characteristics $(n=116)$

\begin{tabular}{|c|c|}
\hline Characteristic & $\begin{array}{l}\text { n (\%) or mean } \\
\text { (SD) }\end{array}$ \\
\hline Age, years, median (range) & $74(70-90)$ \\
\hline Female & $62(53)$ \\
\hline White/Caucasian & $101(87)$ \\
\hline Married & $76(66)$ \\
\hline College graduate or higher & $71(6 I)$ \\
\hline History of prior colorectal cancer screening & $105(92)$ \\
\hline Dementia screen, mean (six-item recall) ${ }^{60}$ & $5.6(0.6)$ \\
\hline Literacy score, mean (seven-item SF-REALM) ${ }^{61}$ & $6.8(0.6)$ \\
\hline Depression screen, mean (PHQ-2) ${ }^{62}$ & $0.5(1.0)$ \\
\hline MacArthur Scale of Subjective Social Status, mean ${ }^{63}$ & $4.4(1.6)$ \\
\hline \multicolumn{2}{|l|}{ Four-year mortality-related index ${ }^{64}$} \\
\hline $4 \%$ predicted mortality & $34(29)$ \\
\hline $15 \%$ predicted mortality & $64(55)$ \\
\hline $42 \%$ predicted mortality & $17(15)$ \\
\hline $64 \%$ predicted mortality & $\mathrm{I}(\mathrm{I})$ \\
\hline \multicolumn{2}{|l|}{ Self-reported health $(\text { SF-I })^{26}$} \\
\hline Excellent & $22(19)$ \\
\hline Very good & $37(32)$ \\
\hline Good & $35(30)$ \\
\hline Fair & $19(16)$ \\
\hline Poor & $3(3)$ \\
\hline Timed up and go, mean (seconds) $)^{27, a}$ & $9.04(2.53)$ \\
\hline \multicolumn{2}{|l|}{ Trail-Making Test, mean (seconds) $)^{30}$} \\
\hline A & $40.3(29.2)$ \\
\hline $\mathrm{B}^{\mathrm{b}}$ & $84.3(42.1)$ \\
\hline
\end{tabular}

Notes: ${ }^{2}$ Two participants were unable to perform the up and go test; ${ }^{b}$ six participants were unable to perform the Trail-Making Test (B) in under 5 minutes.

Abbreviations: SF-REALM, Short Form Rapid Estimate of Adult Literacy in Medicine; PHQ, Patient Health Questionnaire; SF-I, Short Form - I Health Survey. preferred a home-screening test involving less discomfort and no recovery time to either one of the tests that required testing to be completed in a medical facility, involved moderate discomfort, and had varying recovery times, as well as preparation times. Moreover, on a test-attribute level, individuals showed a preference for a greater reduction in mortality over a lower reduction in mortality. Similarly, individuals expressed a preference for a lower risk of complications to a higher risk of complications. Interestingly, individuals assigned slightly higher utility to a test performed every 5 years over a test performed every 10 years. However, participants ascribed the lowest utility to a test performed each year. Lastly, the utility score participants assigned to the option "None: I would not choose either of these" was a strongly negative utility score. This negative utility score indicates that individuals have a strong preference for CRC screening.

\section{DCE-derived individual-level most important attribute and simulated preferred test}

Based on the DCE results, the testing procedure was the most important attribute for $35 \%$ of participants, mortality reduction for $26 \%$, test frequency for $19 \%$, and risk of complications for $19 \%$. With regard to the DCE-derived most important attribute, testing procedure was significantly more likely to be the most important attribute than it was to be the second, third, or least important attribute $(P=0.037)$ (Figure 3). Four participants chose the "none" option in at least one DCE choice question. Based on the simulation models, the DCE individual-level utilities suggested that $43 \%$ would prefer a sigmoidoscopy-equivalent test, $36 \%$ of participants would prefer an FOBT-equivalent test, and 21\% would prefer a colonoscopy-equivalent test. A sigmoidoscopy-equivalent test was significantly more likely to be an individual's preferred test than an FOBT-equivalent test or colonoscopy-equivalent test $(P=0.01)$.

The most important attribute from the DCE was also significantly associated with the directly selected unlabeled test choice. Sixty-three percent (29) of the 46 participants who directly selected the FOBT-equivalent test had testing procedure as their most important attribute, and 52\% (21) of the 40 who selected the colonoscopy-equivalent test had mortality reduction as the most important attribute $(P<0.001)$ (Figure 4). Neither general health status, functional status, nor cognitive status were significantly associated with any test attribute in a bivariate multinomial logistic regression $(P<0.1)$. Neither was the risk of complications or testing-procedure attributes significantly more important than 


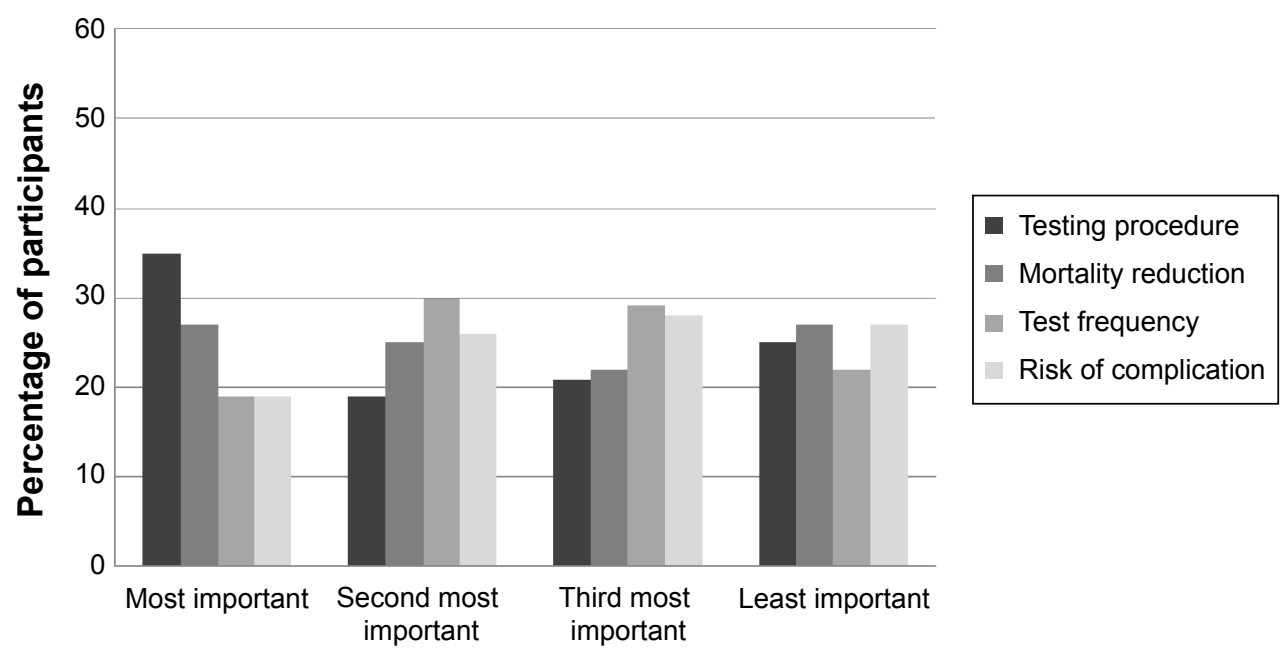

Attribute importance

Figure 3 DCE-derived individual level attribute-importance scores $(n=1 \mid 6)$.

Note: Using $\chi^{2}$ goodness of fit, testing procedure was the most important attribute $(P=0.037)$.

Abbreviation: DCE, discrete choice experiment.

mortality reduction or test frequency in those in best health compared to those in the less healthy groups.

\section{Comparisons between DCE-derived and directly selected most important attribute and test}

Mortality reduction was directly selected as the most important attribute by $48 \%$ of participants $(P<0.001)$, and testing procedure was directly selected as least important by $45 \%$ of participants $(P<0.001)$. A $\chi^{2}$ test of symmetry revealed statistically significant differences in the overall comparisons between most important attribute derived from the DCE versus direct selection $(P<0.001)$, though there was fair agreement between participant's DCE-derived most important attribute and their directly selected most important attribute (47\% agreement, $\kappa=0.28 ; P<0.001$ ) (Table 3 ).

The directly selected unlabeled test choice revealed that $40 \%$ selected the FOBT-equivalent test, 26\% selected the sigmoidoscopy-equivalent test, and $34 \%$ selected the colonoscopy-equivalent test. No participant selected to forgo

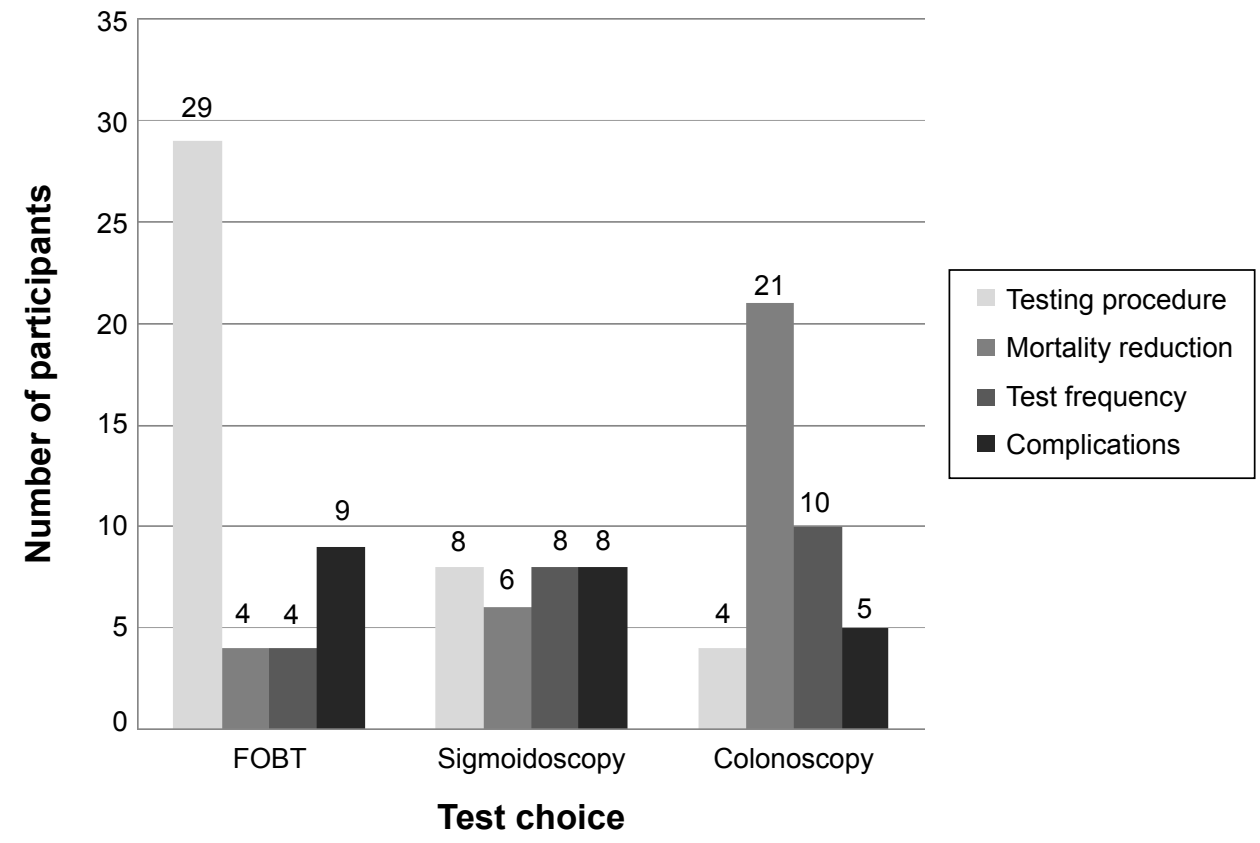

Figure 4 Directly selected unlabeled test choice broken down by DCE-derived most important attribute $(\mathrm{n}=116)$.*

Note: *Using Pearson's $\chi^{2}$ test, most important attribute significantly differed by test choice $(P<0.00 \mathrm{I})$.

Abbreviations: DCE, discrete choice experiment; FOBT, fecal occult blood test. 
Table 3 Agreement between DCE-derived most important attribute and directly selected most important attribute ( $\mathrm{n}=\mathrm{I}$ I6)

\begin{tabular}{|c|c|c|c|c|}
\hline \multirow{2}{*}{$\begin{array}{l}\text { DCE-derived most } \\
\text { important attribute }\end{array}$} & \multicolumn{4}{|c|}{ Directly selected most important attribute } \\
\hline & Testing procedure & Mortality reduction & Test frequency & Complications \\
\hline Testing procedure & 16 & 11 & 5 & 9 \\
\hline Mortality reduction & I & 25 & 4 & I \\
\hline Test frequency & 0 & 9 & 8 & 5 \\
\hline Complications & 3 & 11 & 3 & 5 \\
\hline
\end{tabular}

Note: Bold numbers show the agreement between DCE-derived most important attribute and the directly selected most important attribute.

Abbreviation: DCE, discrete choice experiment.

screening. Comparing these choices with the DCE-derived preferred test revealed significant differences in the proportion of participants choosing each test between the two methods $(P=0.012)$; the agreement between the two methods was fair $(\kappa=0.32, P<0.001)$, with $54 \%$ of participants making the same choice (Table 4$)$.

\section{Common themes surrounding participants' explanation of directly selected unlabeled test choice}

When participants were asked to explain their directly selected unlabeled test choice, several themes emerged (Table 5). More than half of participants weighed at least two different attributes when making their decision; conversely, 50 participants mentioned only one attribute in explaining their decision (of whom $42 \%$ mentioned testing procedure). Fourteen participants did not like the home aspect of the FOBT test, and 13 reported that they chose the sigmoidoscopy because they felt that 10 years was too long to wait to have a repeat test. A few participants seemed to misunderstand the mortality reduction levels, believing that a mortality reduction of five in 1,000 was better than a reduction of 20 in 1,000; others cited their prior experiences with testing as part of their justification.

\section{Discussion}

In this sample of community-dwelling older adults, we found no overwhelming preference for most important CRC-screening test attribute or preferred screening test choice, although the testing procedure was the most important attribute and sigmoidoscopy the most preferred

Table 4 Agreement between DCE-derived preferred test and directly selected unlabeled test choice $(n=116)$

\begin{tabular}{llll}
\hline $\begin{array}{lll}\text { DCE-derived } \\
\text { preferred test }\end{array}$ & \multicolumn{2}{l}{ Directly selected unlabeled test choice } \\
\cline { 2 - 4 } & FOBT & Sigmoidoscopy & Colonoscopy \\
\hline FOBT & $\mathbf{2 9}$ & 10 & 3 \\
Sigmoidoscopy & 15 & 16 & 19 \\
Colonoscopy & 2 & 4 & 18 \\
\hline
\end{tabular}

Note: Bold numbers show the agreement betwen DCE-derived preferred test and the directly selected unlabeled test choice.

Abbreviations: DCE, discrete choice experiment; FOBT, fecal occult blood test. test derived from DCE. Similar to our other work, we found some differences in the results from the DCE versus direct selection. ${ }^{18,49,50}$ The DCE-derived attributes and preferred test were significantly different from the directly selected most important attribute and the unlabeled test choice. As opposed to the DCE-derived most important attribute (testing procedure), mortality reduction was directly selected as the most important attribute, and as opposed to the DCE-derived preference for sigmoidoscopy, FOBT was the most selected unlabeled test choice. Ultimately, we were not able to determine which method provided the superior means of preference elicitation.

The DCE-derived results revealed that testing procedure occurred most frequently as the most important attribute, though a majority of older adults directly selected mortality reduction as their most important attribute. Prior discrete choice work in younger adults (with mean ages between 57 and 61 years) found mortality reduction (or a similar attribute - test accuracy) to be the most important. . $^{17,18,51}$ Although procedure was the most important DCE-derived attribute in our study, the other attributes were also relatively important. In addition to this distribution of preferences, we also found no association between a participant's most important attribute and their overall health status, functional status, or cognitive status. While the DCE-derived most important attribute was associated with the directly selected unlabeled test choice, no other characteristic predicted a participant's preference for one attribute over another. This result confirms previous work, which has shown little evidence of systematic patterns of preferences within subgroups of adults. ${ }^{51}$ In addition, older adults may have set patterns of behavior that are not fully modified in the face of changing health or functional status. Our prior work has shown a strong desire for ongoing screening, even in the face of serious comorbid disease and regardless of life expectancy. ${ }^{52,53}$

Preferences for both the DCE-derived test and directly selected unlabeled test were diverse. The DCEderived simulated test-choice results revealed that the sigmoidoscopy-equivalent test was preferred only slightly more 
Table 5 Common themes surrounding participants' unlabeled test choice $(n=I \mid 6)$

\begin{tabular}{|c|c|c|}
\hline Themes & Frequency (\%) & Quotation \\
\hline Weighed multiple attributes & $63(54)$ & $\begin{array}{l}\text { - Because the risk of complications is acceptable, the time frame is good, } \\
\text { and the reduction of death is acceptable. I don't worry about the discomfort, } \\
\text { so I don't base it on that. }\end{array}$ \\
\hline Focused on a single attribute & $50(43)$ & $\begin{array}{l}\text { - The fact that it's a home test with mild discomfort. } \\
\text { - No prep time. }\end{array}$ \\
\hline $\begin{array}{l}\text { Didn't like the home-based aspect } \\
\text { of the testing procedure }\end{array}$ & $14(12)$ & $\begin{array}{l}\text { - The test would be more valid done at a doctor's office compared to the home. } \\
\text { - It's more precise: having a doctor perform it is better than my doing it at home. }\end{array}$ \\
\hline $\begin{array}{l}\text { Felt that a shorter testing interval } \\
\text { equated with higher quality }\end{array}$ & $13(11)$ & $\begin{array}{l}\text { - I think I have a better chance when I am tested every } 5 \text { years and not waiting } \\
\text { every } 10 \text { years. } \\
\text { - Every } 5 \text { years is better than } 10 \text { years, because } 10 \text { years could be too long } \\
\text { to catch anything. }\end{array}$ \\
\hline $\begin{array}{l}\text { May not have understood } \\
\text { the attribute levels }\end{array}$ & $10(8)$ & $\begin{array}{l}\text { - I like the cancer ratio of 5:I,000 ratio. } \\
\text { - I like it at home with mild discomfort and the risk is better, as well as the } \\
\text { death reduction. }\end{array}$ \\
\hline $\begin{array}{l}\text { Prior experience with tests used } \\
\text { as justification for choice }\end{array}$ & $9(7)$ & $\begin{array}{l}\text { - Because I have had similar tests to this one. } \\
\text { - There's no prep time and the prep is such a nightmare for me, and it makes me } \\
\text { dread the test so much. }\end{array}$ \\
\hline
\end{tabular}

Abbreviation: prep, preparation.

often than colonoscopy-equivalent test and FOBT-equivalent test ( $43 \%$ versus $21 \%$ and $36 \%$, respectively); this result is different to the directly selected test preference at a cursory evaluation. However, the DCE-derived results do not seem clinically different from the directly labeled choice, where participants preferred FOBT only slightly more than colonoscopy and sigmoidoscopy ( $40 \%$ versus $34 \%$ and $26 \%$, respectively). On the other hand, other studies have shown that most patients not only receive colonoscopy over other modalities, ${ }^{54,55}$ but also older adults have tended to report preferences for colonoscopy or FOBT over sigmoidoscopy. ${ }^{51,56}$ Additionally, a study of CRC test preference in younger veterans using a type of DCE found $63 \%$ of participants preferred colonoscopy. ${ }^{16}$ One potential explanation is that the participants had definite preferences for test attributes but that the existing tests do not possess all of these attributes..$^{51}$ Therefore, our results may indicate that older adults value a combination of attributes that are not currently reflected in existing tests or in tests assessed in this study. It is possible that newer tests not evaluated in this study, such as computed tomographic colonography or fecal deoxyribonucleic acid (DNA) testing, may have attributes valued by older adults.

Although significant time and effort was spent developing and refining the attributes and levels used in the DCE to maximize participant understanding, some individuals appeared to have preferences based on beliefs that may seem counterintuitive. Notably, some individuals preferred a shorter test frequency than every 10 years, which shifts the DCE-derived preferred test toward sigmoidoscopy over colonoscopy (which is recommended every 5 years versus every 10 years, respectively). Again our qualitative work found some individuals were uncomfortable with the idea of a 10-year screening interval, even though efforts were made to dissociate screening interval and efficacy in our explanations prior to DCE administration. Nonetheless, confirming our findings, younger adults have shown a preference for screening intervals shorter than 10 years in a prior study. ${ }^{14}$ Therefore, while these results may appear counterintuitive, we found, like others, that participants were making deliberate decisions that were logical choices in their own minds, given their preferences, and we therefore included all responses in our sample. ${ }^{57,58}$

Ultimately, we do not know why individuals made the choices that they did. Possible explanations for seemingly counterintuitive responses include the following: some individuals did not understand the information provided, the survey did not capture attributes and levels that were important to participants, or individuals made rational decisions based on their own decisional framework, which other individuals may find irrational. Of note, while we assessed literacy, which was generally high, we did not assess numeracy, which would lend credence to the idea that participants did not understand the levels provided.

Future efforts will need to determine how best to disentangle the accuracy/quality of screening tests and frequency. Although we found evidence of counterintuitive choices, the qualitative results reveal that most of the older adults seemed able to perform the DCE. Moreover, we are heartened to see from our qualitative work that more than half the time, older adults were weighing multiple attributes when making their decisions. 
Our qualitative data suggest that older adults may desire office-based tests, perhaps because they feel that home tests are less accurate because they may have difficulties performing them correctly. ${ }^{59}$ The US Preventive Services Task Force (USPSTF) does not recommend office-based FOBT tests, and as such providers only perform sigmoidoscopy and colonoscopy in the office-based setting. Therefore, participants may also entangle test accuracy and location of test. In the future, it will be important to determine if improved explanations of attributes will separate test accuracy from either test frequency or location in participants' choices and help reduce potentially inappropriate responses. However, it is possible that people may just have office-based preferences or prefer shorter intervals.

This study has several limitations, including its lack of generalizability due to the use of a sample of highly educated older adults who had overall screening rates of $92 \%$. The high screening rates may have resulted in only four participants choosing the "none" option in the DCE. The differences in DCE-derived most important attributes and directly selected most important attribute may have been due to only listing the general labels of each of the attributes in the directly selected question and not including their full definitions as were presented in the information provided prior to the DCE questions. However, participants had just finished the DCE, and thus were expected still to recall the definitions of each attribute. Another reason may be that participants may have felt an internal or external pressure to report that mortality reduction is the most important attribute during the direct selection portion of the survey. Furthermore, the age range of the sample included in the study exceeded the USPSTF guidelines for screening. We chose this range because individuals continue to receive screening well beyond recommended ages. ${ }^{39-41}$ However, it is possible that the data may have resulted in different outcomes if individuals over 85 years had been excluded from the sample. While we conducted extensive formative work to develop the attributes and attribute levels to obtain a robust subset of attributes and range of levels to use in the DCE, and we believe the attributes and levels we selected are appropriate and well supported in the literature, it is possible including other attributes or levels may have yielded different results. Similarly, choice simulations predict market choices under ideal conditions, and are a relative indicator of preference. ${ }^{47}$ However, simulations may also significantly differ from actual test choice if different attributes and levels are employed.

Our work has several implications for clinical practice. For one, providers should not assume that older adults have a monolithic preference for a particular screening test. Additionally, the association between most important attribute and preferred test suggests that providers may find it useful to ask about which test attributes are important to an individual and point to the test that best matches their preferences. It also highlights the need for providers to ensure full understanding of test attributes so that patients are making a truly informed decision, guaranteeing they fully appreciate the degree of mortality reduction or associated complications. Lastly, with further work, this DCE potentially could serve as a decision aid given to older patients who have made the decision to undergo CRC screening.

In conclusion, our findings suggest older adults do not overwhelmingly value any one CRC-screening test attribute or prefer a single type of CRC-screening test more than others, although small absolute DCE-derived preferences for testing procedure and sigmoidoscopy were demonstrated. Our current work highlights the fact that older adults' preferences for CRC-screening tests are not easily predicted and that providers should actively elicit them. However, an individualized discussion about CRC-screening test choice may be impractical within the time constraints of a typical patient-provider encounter. Future work will need to explore which interventions are most effective to support the complex decision making needed in an older population and how best to deliver them.

\section{Acknowledgments}

CEK was supported by award K12 HS19468-01 from the UNC Mentored Career Development Program in Comparative Effectiveness Development and the University Cancer Research Fund from the Lineberger Comprehensive Cancer Center. A presentation describing the results of this manuscript was given at the 4th Annual Conjoint Analysis in Healthcare Conference on March 21, 2012. Additionally, this manuscript was presented as a poster on May 4, 2012 at the annual American Geriatrics Society national conference. We would like to thank Dana Mueller and Carmel Hannah for their assistance with data collection. We would also like to thank the data-collection sites, North Carolina State University's Adult Development Laboratory and the Department of Family Medicine at the University of North Carolina at Chapel Hill, for their time and effort.

\section{Disclosure}

The authors report no conflicts of interest in this work.

\section{References}

1. U. S. Preventive Services Task Force. Screening for colorectal cancer: U.S. Preventive Services Task Force recommendation statement. Ann Intern Med. 2008;149(9):627-637. 
2. Smith RA, Cokkinides V, Brawley OW. Cancer screening in the United States, 2009: a review of current American Cancer Society guidelines and issues in cancer screening. CA Cancer J Clin. 2009;59(1): $27-41$.

3. [No authors listed]. Colon cancer screening (USPSTF recommendation). U.S. Preventive Services Task Force. J Am Geriatr Soc. 2000;48(3): 333-335.

4. Centers for Disease Control Prevention (CDC). Vital signs: colorectal cancer screening test use - United States, 2012. MMWR Morb Mortal Wkly Rep. 2013;62(44):881-888.

5. Klabunde CN, Shapiro JA, Kobrin S, Nadel MR, Zapka JM. Colorectal cancer screening in US seniors ages 76-84 Years. J Community Health. Epub 2015 Feb 26.

6. Holden DJ, Jonas DE, Porterfield DS, Reuland D, Harris R. Systematic review: enhancing the use and quality of colorectal cancer screening. Ann Intern Med. 2010;152(10):668-676.

7. Inadomi JM, Vijan S, Janz NK, et al. Adherence to colorectal cancer screening: a randomized clinical trial of competing strategies. Arch Intern Med. 2012;172(7):575-582.

8. Kuipers EJ, Rösch T, Bretthauer M. Colorectal cancer screening optimizing current strategies and new directions. Nat Rev Clin Oncol. 2013;10(3):130-142.

9. Ling BS, Trauth JM, Fine MJ, et al. Informed decision-making and colorectal cancer screening: is it occurring in primary care? Med Care. 2008;46(9 Suppl 1):S23-S29.

10. Wolf MS, Baker DW, Makoul G. Physician-patient communication about colorectal cancer screening. J Gen Intern Med. 2007;22(11) 1493-1499.

11. Clark MD, Determann D, Petrou S, Moro D, de Bekker-Grob EW. Discrete choice experiments in health economics: a review of the literature. Pharmacoeconomics. 2014;32(9):883-902.

12. Wortley S, Wong G, Kieu A, Howard K. Assessing stated preferences for colorectal cancer screening: a critical systematic review of discrete choice experiments. Patient. 2014;7(3):271-282.

13. Gyrd-Hansen D, Søgaard J. Analysing public preferences for cancer screening programmes. Health Econ. 2001;10(7):617-634.

14. van Dam L, Hol L, de Bekker-Grob EW, et al. What determines individuals' preferences for colorectal cancer screening programmes? A discrete choice experiment. Eur J Cancer. 2010;46(1):150-159.

15. Hol L, de Bekker-Grob EW, van Dam L, et al. Preferences for colorectal cancer screening strategies: a discrete choice experiment. Br J Cancer. 2010;102(6):972-980.

16. Imaeda A, Bender D, Fraenkel L. What is most important to patients when deciding about colorectal screening? J Gen Intern Med. 2010; 25(7):688-693.

17. Hawley ST, Volk RJ, Krishnamurthy P, Jibaja-Weiss M, Vernon SW, Kneuper S. Preferences for colorectal cancer screening among racially/ ethnically diverse primary care patients. Med Care. 2008;46(9 Suppl 1) S10-S16.

18. Pignone MP, Brenner AT, Hawley S, et al. Conjoint analysis versus rating and ranking for values elicitation and clarification in colorectal cancer screening. J Gen Intern Med. 2012;27(1):45-50.

19. Salkeld G, Solomon M, Short L, Ryan M, Ward JE. Evidence-based consumer choice: a case study in colorectal cancer screening. Aust $N$ Z J Public Health. 2003;27(4):449-455.

20. Frew E, Wolstenholme JL, Whynes DK. Willingness-to-pay for colorectal cancer screening. Eur J Cancer. 2001;37(14):1746-1751.

21. Marshall DA, Johnson FR, Phillips KA, Marshall JK, Thabane L, Kulin NA. Measuring patient preferences for colorectal cancer screening using a choice-format survey. Value Health. 2007;10(5):415-430.

22. Nayaradou M, Berchi C, Dejardin O, Launoy G. Eliciting population preferences for mass colorectal cancer screening organization. Med Decis Making. 2010;30(2):224-233.

23. Howard K, Salkeld G. Does attribute framing in discrete choice experiments influence willingness to pay? Results from a discrete choice experiment in screening for colorectal cancer. Value Health. 2009; 12(2):354-363.
24. Wolff JL, Starfield B, Anderson G. Prevalence, expenditures, and complications of multiple chronic conditions in the elderly. Arch Intern Med. 2002;162(20):2269-2276.

25. Walter LC, Covinsky KE. Cancer screening in elderly patients: a framework for individualized decision making. JAMA. 2001; 285(21):2750-2756

26. Kaplan GA, Camacho T. Perceived health and mortality: a nine-year follow-up of the human population laboratory cohort. Am J Epidemiol. 1983;117(3):292-304

27. Steffen TM, Hacker TA, Mollinger L. Age- and gender-related test performance in community-dwelling elderly people: Six-Minute Walk Test, Berg Balance Scale, Timed Up \& Go Test, and gait speeds. Phys Ther. 2002;82(2):128-137.

28. Robinson TN, Wallace JI, Wu DS, et al. Accumulated frailty characteristics predict postoperative discharge institutionalization in the geriatric patient. J Am Coll Surg. 2011;213(1):37-42; discussion 42-44.

29. Pua YH. Allometric analysis of physical performance measures in older adults. Phys Ther. 2006;86(9):1263-1270.

30. Tombaugh TN. Trail Making Test A and B: normative data stratified by age and education. Arch Clin Neuropsychol. 2004;19(2):203-214.

31. Louviere JJ, Hensher DA, Swait JD. Stated Choice Methods: Analysis and Application. Cambridge: Cambridge University Press; 2000.

32. Orme BK. Interpreting the results of conjoint analysis. In: Orme BK. Getting Started with Conjoint Analysis: Strategies for Product Design and Pricing Research. 2nd ed. Madison: Research Publishers; 2010:77-88

33. Orme BK. Formulating attributes and levels in conjoint analysis. In: Orme BK. Getting Started with Conjoint Analysis: Strategies for Product Design and Pricing Research. 2nd ed. Madison: Research Publishers; 2010:51-56.

34. Pignone M, Rich M, Teutsch SM, Berg AO, Lohr KN. Screening for colorectal cancer in adults at average risk: a summary of the evidence for the U.S. Preventive Services Task Force. Ann Intern Med. 2002;137(2):132-141.

35. Kewenter J, Brevinge H. Endoscopic and surgical complications of work-up in screening for colorectal cancer. Dis Colon Rectum. 1996;39(6):676-680.

36. Bridges JF, Hauber AB, Marshall D, et al. Conjoint analysis applications in health - a checklist: a report of the ISPOR Good Research Practices for Conjoint Analysis Task Force. Value in Health. 2011;14(4):403-413.

37. Luck T, Luppa M, Briel S, Riedel-Heller SG. Incidence of mild cognitive impairment: a systematic review. Dement Geriatr Cogn Disord. 2010;29(2):164-175.

38. Callahan CM, Unverzagt FW, Hui SL, Perkins AJ, Hendrie HC. Six-item screener to identify cognitive impairment among potential subjects for clinical research. Med Care. 2002;40(9):771-781.

39. Bellizzi KM, Breslau ES, Burness A, Waldron W. Prevalence of cancer screening in older, racially diverse adults: still screening after all these years. Arch Intern Med. 2011;171(22):2031-2037.

40. Chen X, White MC, Peipins LA, Seeff LC. Increase in screening for colorectal cancer in older Americans: results from a national survey. J Am Geriatr Soc. 2008;56(8):1511-1516.

41. Royce TJ, Hendrix LH, Stokes WA, Allen IM, Chen RC. Cancer screening rates in individuals with different life expectancies. JAMA Intern Med. 2014;174(10):1558-1565.

42. Orme BK. Sample size issues for conjoint analysis. In: Orme BK. Getting Started with Conjoint Analysis: Strategies for Product Design and Pricing Research. 2nd ed. Madison: Research Publishers; 2010:57-66.

43. Johnson RM. Understanding HB: An Intuitive Approach. Sequim (WA): Sawtooth Software; 2000. Available from: https://sawtoothsoftware. com/download/techpap/undhb.pdf. Accessed April 8, 2015.

44. Ryan M, Farrar S. Using conjoint analysis to elicit preferences for health care. BMJ. 2000;320(7248):1530-1533.

45. Ryan M, Gerard K. Using discrete choice experiments to value health care programmes: current practice and future research reflections. Appl Health Econ Health Policy. 2003;2(1):55-64. 
46. Orme B. CBC/Web Analysis Module and Market Simulator. Sequim (WA): Sawtooth Software; 2001.

47. Orme BK. Market simulators for conjoint analysis. In: Orme BK. Getting Started with Conjoint Analysis: Strategies for Product Design and Pricing Research. 2nd ed. Madison: Research Publishers; 2010:89-103.

48. Grbich C. Qualitative Data Analysis: An Introduction. 2nd ed. London: Sage Publications; 2013.

49. Pignone MP, Crutchfield TM, Brown PM, et al. Using a discrete choice experiment to inform the design of programs to promote colon cancer screening for vulnerable populations in North Carolina. BMC Health Serv Res. 2014;14:611.

50. Brenner A, Howard $\mathrm{K}$, Lewis $\mathrm{C}$, et al. Comparing 3 values clarification methods for colorectal cancer screening decision-making: a randomized trial in the US and Australia. J Gen Intern Med. 2014;29(3):507-513.

51. Shokar NK, Carlson CA, Weller SC. Informed decision making changes test preferences for colorectal cancer screening in a diverse population. Ann Fam Med. 2010;8(2):141-150.

52. Kistler CE, Lewis CL, Amick HR, Bynum DL, Walter LC, Watson LC. Older adults' beliefs about physician-estimated life expectancy: a crosssectional survey. BMC Fam Pract. 2006;7:9.

53. Lewis CL, Kistler CE, Amick HR, et al. Older adults' attitudes about continuing cancer screening later in life: a pilot study interviewing residents of two continuing care communities. BMC Geriatr. 2006;6:10.

54. Meissner HI, Breen N, Klabunde CN, Vernon SW. Patterns of colorectal cancer screening uptake among men and women in the United States. Cancer Epidemiol Biomarkers Prev. 2006;15(2):389-394.

55. Fenton JJ, Jerant AF, von Friederichs-Fitzwater MM, Tancredi DJ, Franks P. Physician counseling for colorectal cancer screening: impact on patient attitudes, beliefs, and behavior. J Am Board Fam Med. 2011; 24(6):673-681.
56. Wolf A, Schorling JB. Does informed consent alter elderly patients' preferences for colorectal cancer screening? J Gen Intern Med. 2001; 15(1):24-30.

57. Ryan M, Watson V, Entwistle V. Rationalising the 'irrational': a think aloud study of discrete choice experiment responses. Health Econ. 2009; 18(3):321-336.

58. Lancsar E, Louviere J. Deleting 'irrational' responses from discrete choice experiments: a case of investigating or imposing preferences? Health Econ. 2006;15(8):797-811.

59. Beeker C, Kraft JM, Southwell BG, Jorgensen CM. Colorectal cancer screening in older men and women: qualitative research findings and implications for intervention. J Community Health. 2000;25(3):263-278.

60. Callahan CM, Unverzagt FW, Hui SL, Perkins AJ, Hendrie HC. Six-item screener to identify cognitive impairment among potential subjects for clinical research. Med Care. 2002;40(9):771-781.

61. Arozullah AM, Yarnold PR, Bennett CL, et al. Development and validation of a short-form, rapid estimate of adult literacy in medicine. Med Care. 2007;45(11):1026-1033.

62. Kroenke K, Spitzer RL, Williams JB. The Patient Health Questionnaire-2: validity of a two-item depression screener. Med Care. 2003;41(11):1284-1292.

63. Adler NE, Epel ES, Castellazzo G, Ickovics JR. Relationship of subjective and objective social status with psychological and physiological functioning: preliminary data in healthy white women. Health Psychol. 2000;19(6):586-592.

64. Lee SJ, Lindquist K, Segal MR, Covinsky KE. Development and validation of a prognostic index for 4-year mortality in older adults. JAMA. 2006;295(7):801-808.
Patient Preference and Adherence

\section{Publish your work in this journal}

Patient Preference and Adherence is an international, peer-reviewed, open access journal that focuses on the growing importance of patient preference and adherence throughout the therapeutic continuum. Patient satisfaction, acceptability, quality of life, compliance, persistence and their role in developing new therapeutic modalities and compounds to optimize

\section{Dovepress}

clinical outcomes for existing disease states are major areas of interest for the journal. This journal has been accepted for indexing on PubMed Central. The manuscript management system is completely online and includes a very quick and fair peer-review system, which is all easy to use. Visit http://www. dovepress.com/testimonials.php to read real quotes from published authors. 